\title{
Mini-open anterior spine surgery for anterior lumbar diseases
}

\author{
Ruey-Mo Lin · Kuo-Yuan Huang · Kuo-An Lai
}

Received: 26 April 2007/Revised: 30 December 2007/Accepted: 8 February 2008/Published online: 8 March 2008

(C) The Author(s) 2008

\begin{abstract}
Minimally invasive surgeries including endoscopic surgery and mini-open surgery are current trend of spine surgery, and its main advantages are shorter recovery time and cosmetic benefits, etc. However, mini-open surgery is easier and less technique demanding than endoscopic surgery. Besides, anterior spinal fusion is better than posterior spinal fusion while considering the physiological loading, back muscle function, etc. Therefore, we aimed to introduce the modified "mini-open anterior spine surgery" (MOASS) and to evaluate the feasibility, effectiveness and safety in the treatment of various anterior lumbar diseases with this technique. A total of 61 consecutive patients (46 female, 15 male; mean age 58.2 years) from 1997 to 2004 were included in this study, with an average follow-up of 24-52 (mean 43) months. The disease entities included vertebral fracture (20), failed back surgery (13), segmental instability or spondylolisthesis (10), infection (8), herniated disc (5), undetermined lesion for biopsy (4), and hemivertebra (1). Lesions involved 13 cases at T12-L1, 18 at L1-L2, 18 at L2-L3, 22 at L3-L4 and 11 at L4-L5 levels. All patients received a single stage anterior-only procedure for their anterior lumbar disease. We used the subjective clinical results, Oswestry disability index, fusion rate, and complications to evaluate our clinical outcome. Most patients (91.8\%) were subjectively
\end{abstract}

\section{R.-M. Lin $(\bowtie) \cdot$ K.-A. Lai}

Department of Orthopedics, College of Medicine,

National Cheng Kung University Hospital,

138 Sheng Li Road, Tainan 70428, Taiwan

e-mail: linrm@mail.ncku.edu.tw

\section{K.-Y. Huang}

Department of Orthopedics and Institute of Clinical Medicine, College of Medicine, National Cheng Kung University Hospital,

Tainan, Taiwan satisfied with the surgery and had good-to-excellent outcomes. Mean operation time was 85 (62-124) minutes, and mean blood loss was 136 (minimal-250) $\mathrm{ml}$ in the past 6 years. Hospital stay ranged from 4-26 (mean 10.6) days. Nearly all cases had improved back pain (87\%), physical function (90\%) and life quality (85\%). Most cases (95\%) achieved solid or probable solid bony fusion. There were no major complications. Therefore, MOASS is feasible, effective and safe for patients with various anterior lumbar diseases.

Keywords Mini-open anterior spine surgery . Mini-open - Anterior lumbar interbody fusion . Techniques $\cdot$ Lumbar fusion $\cdot$ ALIF

\section{Introduction}

Anterior lumbar interbody fusion (ALIF) was developed in the early 1930s for the treatment of spondylolisthesis and tuberculosis $[4,15]$. Ley et al. proposed the retroperitoneal approach so that integrity could be maintained in the peritoneum, which minimizes the post-operative bowel problems of previous extensive transperitoneal exposure [17]. Anterior spinal fusion is designed to stabilize anterior column injuries/lesions by fusing the target segments. The axial physiological load is $80 \%$ through the anterior column and 20\% through the posterior elements [7]. Anterior spinal fusion can resist and share the compression force at the anterior column, thus providing a biomechanically superior construct with more physiological support, which may enhance the incorporation of bone graft to host bone, than posterior spinal fusion [7, 12]. ALIF can restore disc height, which opens up the narrowed neural canal and foramen and leaves back muscles and nerves undisturbed [23]. The 
long-term results of ALIF have been reported to be satisfactory in about $80 \%$ of cases, even after 10 years [22, 23].

However, conventional anterior approaches fell out of favor because of vessel injuries, pre-sacral plexus injuries, urinary retention, retrograde ejaculation, and abdominal muscle weakness, and because of the large incision and extensive anatomical dissection $[1,24,26]$. The increasing popularity of posterior implantation also hindered the development of anterior fusion [13, 27]. Although many patients have received posterolateral fusion and implantation, few papers have discussed their long-term effects.

Many efforts have been made to make the anterior approach safer and more reliable. Fraser used a wide, muscle-splitting extraperitoneal approach to the lumbar spine [10]. The development of minimally invasive techniques such as endoscopic surgery and mini-open surgery has revived anterior lumbar spinal surgery. The advantages of anterior spinal fusion can be achieved safely and easily $[9,20]$. Compared to endoscopic surgery, mini-open anterior lumbar surgery is easier to learn, less expensive, and offers direct vision and a more hands-on approach [9, 20]. Indications for minimally invasive spinal surgery are not yet defined [11]. We have attempted to improve upon the surgical and implantation techniques using the mini-open anterior spine surgery (MOASS) to facilitate the management of different anterior lumbar diseases, and we intended to clarify the feasibility, effectiveness and safety of the MOASS technique.

\section{Materials and methods}

From March 1997 to March 2004, 61 consecutive patients (46 female, 15 male) underwent the MOASS surgical technique for a wide variety of anterior lumbar diseases in our hospital. All patients received a single stage anterioronly procedure for their anterior lumbar disease. These procedures were performed by one of the senior authors at our hospital. Thirteen cases had lesions at T12-L1, while 18 were at L1-2, 18 were at L2-L3, 22 were at L3-L4 and 11 were at L4-L5. These patients had postoperative follow-ups of 24-52 (mean 43) months. Ages ranged from 11-78 years (mean 58.2), and durations of pre-operative symptoms and signs ranged from 6 to 96 (mean 23) months. Diagnoses included vertebral fracture $[20$ cases (5 T12; 9 L1; 4 L2; 2 L3; 3 L4)], failed-back syndrome for supplemental or remedial fusion [13 cases $(2$ T12-L1; 3 L1-2; 3 L2-3; 6 L3-4; 4 L4-5)], segmental instability or spondylolisthesis [10 cases (3 L2-3; 5 L3-4; 2 L4-5)], infection [8 cases (1 T12-L1; 2 L1-2; 2 L2-3; 2 L3-4; 1 L4-5)], herniated disc [5 cases (1 T12-L1; 1 L1-2; 2 L2-3; 3 L3-4)], undetermined lesion for biopsy [4 cases (2 L1; 2 L2)] and hemivertebra (1 case, T12). Surgery was done by autograft and/or allograft. Fusion materials included 32 tricortical iliac autografts, 12 allografts, 9 rib grafts [8 cases had polymethylmethacrylate (PMMA) cement hybridized with interpore] and 4 cement grafts. Implants were used only to hold the fusion grafts and limit interference with segmental arteries; two polyaxial screws and one rod were usually enough. Implant types included 38 Moss-Miami, $6 \mathrm{CDH}$, and 2 Diapson. However, implants were not used in 15 cases. The MOASS procedure involved mini-open skin incision by an anterolateral, extraperitoneal approach, to be mentioned below. All patients were allowed to ambulate by Boston brace on the third postoperative day. Muscle strengthening exercises began 2 weeks later. The Boston brace was recommended for removal after 12 weeks.

\section{Surgical techniques}

The surgical technique of MOASS was standardized in this study and was used to treat various lumbar spinal lesions, including vertebral fracture, failed-back syndrome segmental instability or spondylolisthesis, infection, herniated disc, undetermined lesion for biopsy and hemivertebra, etc. Using the MOASS surgical technique, we can perform anterior decompression such as anterior corpectomy or anterior discectomy, and anterior bone grafting and anterior spinal fusion such as ALIF and anterior instrumentation with screws and one rod system directly, and easily.

The patient was put in the lateral decubitus position described by Mayer [20]. A C-arm was used to define the target. A transverse skin incision was usually made just above to the target vertebrae, and in the region between the anterior and middle axillary lines. When the target vertebra was at the T12 rib level, the incision was made one level below. If the target involved two levels (with one disc), a $4 \mathrm{~cm}$ incision was adequate. If the target involved three levels (two discs), the incision was extended to $6-8 \mathrm{~cm}$. For the latter, complete corpectomy of the middle vertebra could be performed smoothly. A headlight or Vario retractor with lamps was used to light up the small operation field.

\section{From L2 to L5}

Muscle splitting, layer-by-layer, from external oblique abdominal muscle, internal oblique abdominal muscle, to transverse abdominal fascia was the method of choice. After reaching the retroperitoneal space, the medial margin was reached by blunt finger dissection. After laterally retracting the psoas muscle, traction screws and blade were used to expose the disc. Ligation of segmental vessels was usually unnecessary for two levels; if three levels were involved, it was usually mid-level. 


\section{From $T 12$ to $L 2$}

The anatomy in this area is widely varied. Incision could be made below the 12th rib, between the 11th and 12th ribs or even up to the 9 th or 10th rib. Due to anatomical variations, not all muscle layers were visible during each operation. For example, if the 11th or 12th rib route was used, we were sometimes unable to see the internal oblique abdominal muscle during the operation. Basically, the latissimus dorsi and external oblique abdominal muscle are at the same level and continuously interdigitated. The diaphragm and transverse abdominal muscle are also interdigitated and at the same muscular level. Severance of muscle layers was the rule to avoid injury to intercostal or subcostal nerves (Fig. 1a). Sometimes, $2-3 \mathrm{~cm}$ had to be cut from the free ends of the 11th or 12th rib. Because the diaphragm and transverse abdominal muscle layers are mostly at the same level, part of the diaphragm was incised on occasion to enter the retroperitoneal space. This had to be done when entering through the 10th and 11th or even the 9th and 10th intercostal space (Fig. 1b, c). In this way, the chest cavity was rarely opened, once the pleura are opened, it is easily sutured and sealed off securely. We will exsufflate the chest cavity at the end of the procedure, so no chest tube is needed. The MOASS technique is a retroperitoneal extrapleural approach. If the target is T12 or L1, the crus of the diaphragm must be dissected longitudinally to expose their vertebral bodies. We can reach the lower part of the T12 vertebra without opening the diaphragm.
Fig. 1 a Dashed line $(a, b, c, d)$ indicates possible incisions for mini-open anterior spinal surgery. The level could be below the 12th rib, between the 11 th and 12th ribs or even up to the 9 th or 10 th rib. Severance of muscle layers was the rule to avoid injuries to the intercostal or subcostal nerves, and usually $2-3 \mathrm{~cm}$ below the target provided adequate exposure; b the ENT forceps indicate the dissected intercostal muscles between the 10th and 11th ribs; a short segment of the 11th rib was already cut. Directly under the intercostalis is the fibrotendinous portion of the transverse abdominal muscle (arrow); c splitting this fibrotendinous portion, the retroperitoneal space was exposed

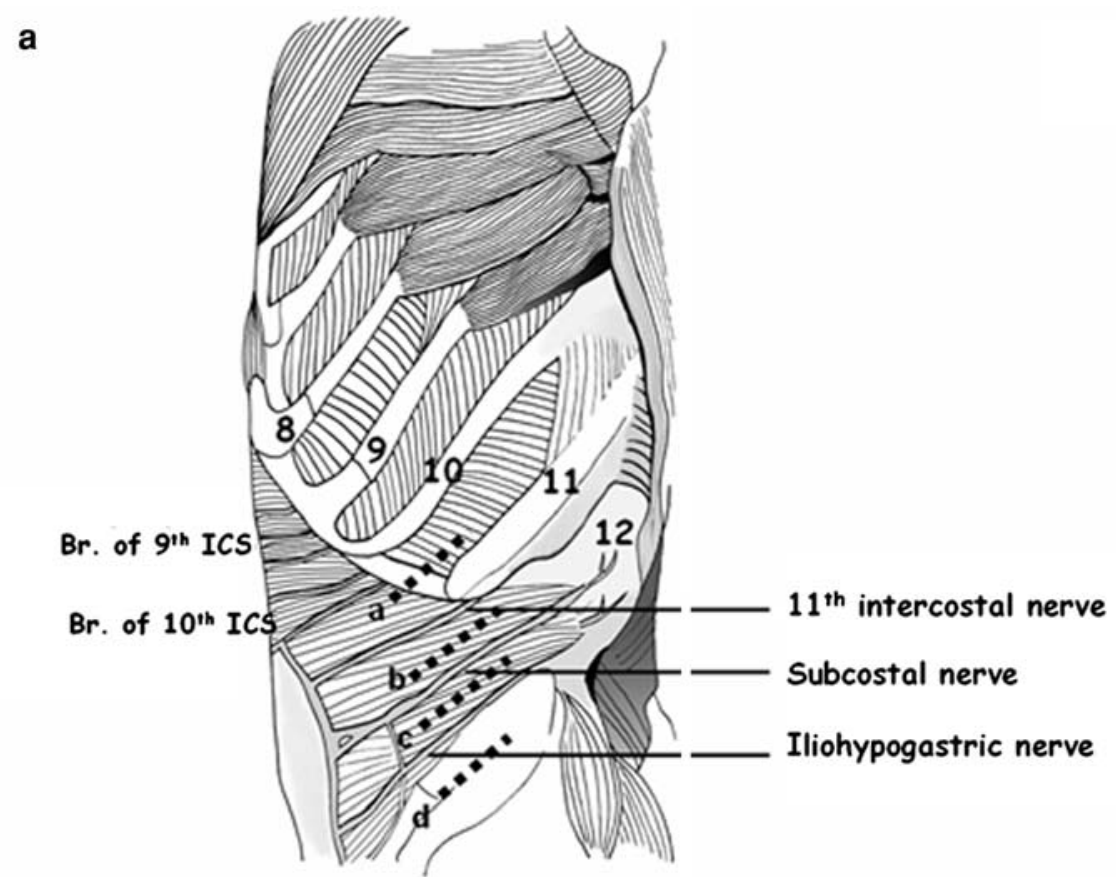

b

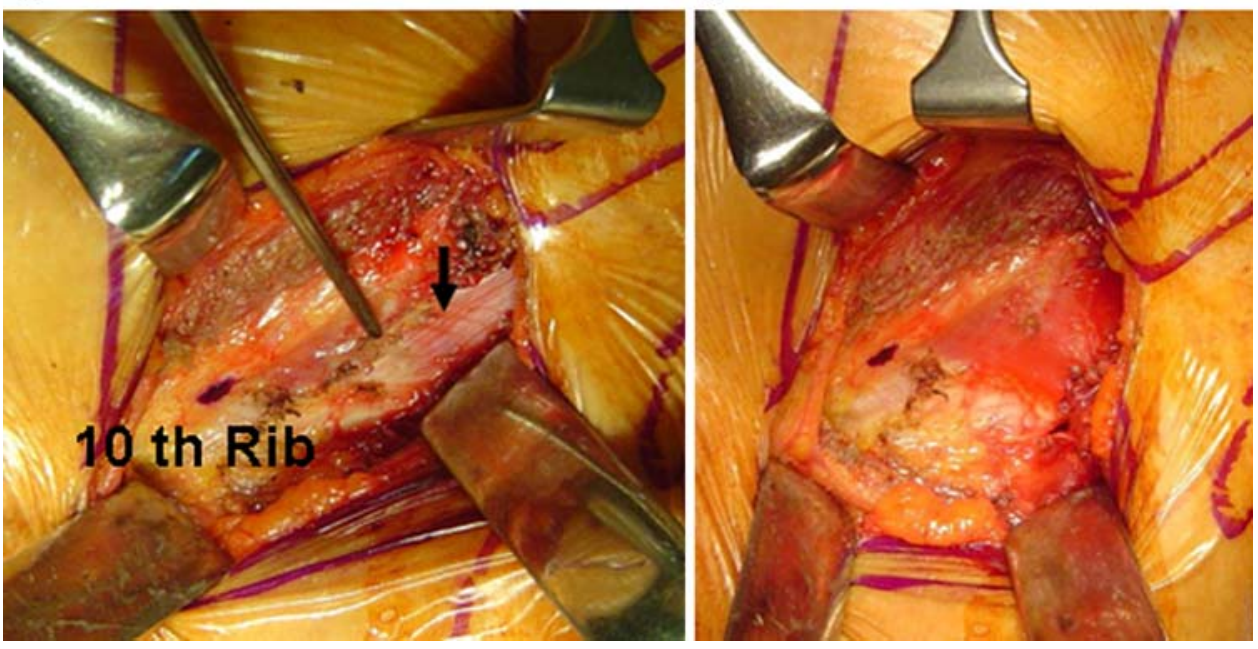


Tricortical iliac autografts, allografts, rib grafts, chip bone mesh, or hybrids of the same were the fusion materials used. After decompression and grafting, polyaxial MOSS-Miami screws were generally used because of their versatility and low profile. During tightening, the rod would not give way, which would have jeopardized vertebral anchoring, especially for osteoporotic bones. The screws were usually inserted upward and downward so that segmental vessels would be spared (Fig. 2). In osteoporotic bone, PMMA cement hybridized with interpore or cement grafts were used for augmentation of fixation; however, no additional posterior surgery was needed.

\section{Evaluation methods}

Subjective clinical results were categorized as excellent, good, fair, or poor. Excellent meant satisfaction with the surgery, no residual symptoms and a return to pre-injury activities. Surgical satisfaction and improved symptoms qualified as good, while dissatisfaction with surgery and residual symptoms were deemed fair. Surgical dissatisfaction and worsened symptoms were regarded as poor results. The disability improvement were evaluated by pre- and post-operative modified Oswestry disability Questionnaires [8, 18].

Fusion grade was evaluated by plain film and dynamic radiograph according to Burkus criteria [3]. 'Solid fusion' was defined as positive bridging trabeculation, the absence of a radiolucent line, and no motion on the F-E view. 'Probable solid fusion' was defined as an incomplete radiolucent line, minimal motion $\left(<5^{\circ}\right)$, and solidity on one side of the graft. 'Failed condition' was defined as graft resorption, a great decrease in graft size, wide motion on the F-E view $\left(>5^{\circ}\right)$, and a full radiolucent line. Increase in disc height and intervertebral angulation immediately after the MOASS technique, and further loss during follow-up, were recorded.

In this study, all 61 patients who underwent the MOASS technique were evaluated in terms of subjective clinical outcome, operation time (minutes), blood loss (ml), hospital stay, disability improvement, fusion rate, and complications, to determine the feasibility, effectiveness, and safety of the MOASS surgical technique in the treatment of various anterior lumbar diseases.

\section{Results}

Most patients (91.8\%) were subjectively satisfied with the surgery and had good-to-excellent outcomes. Mean operation time was $152(67-285) \mathrm{min}$ in the first year, decreasing to $85(62-124)$ min over the next 6 years. Mean blood loss showed even better improvement, from roughly $425(200-1,150) \mathrm{ml}$ in the first year to 136 (minimal-250) $\mathrm{ml}$ over the next 6 years. The maximum reported blood loss of $1,150 \mathrm{cc}$ was related to the coexistence of mycotic aneurysm in a patient with infection; however, the patient was successfully treated by in situ graft replacement. Hospital stay ranged from 4 to 26 (mean 10.6) days. The Oswestry Disability Index indicated that nearly all cases showed improvement in back pain (87\%), physical function $(90 \%)$, and life quality $(85 \%)$. These improvements were most pronounced in sitting endurance, standing endurance, living independence and sleeping quality. Most patients retained these improvements for at least 2 years. Grade of fusion, evaluated by plain film and dynamic radiograph, was solid in 48 cases (79\%), probable solid in 10 cases (16\%) and failed in 3 cases (5\%) (Table 1). Most cases $(95 \%)$ had solid or probable solid bony fusion
Fig. 2 A 57 year-old female who suffered from motion pain and left L5 sciatica for years. Dynamic X-ray showed L4-5 degenerative spondylolisthesis with spinal instability. The MOASS technique was performed and the lower screw was inserted obliquely to avoid ligating the segmental vessels (arrow). She had an excellent clinical outcome; 3.5 years later, we noted solid interbody fusion at L4-5
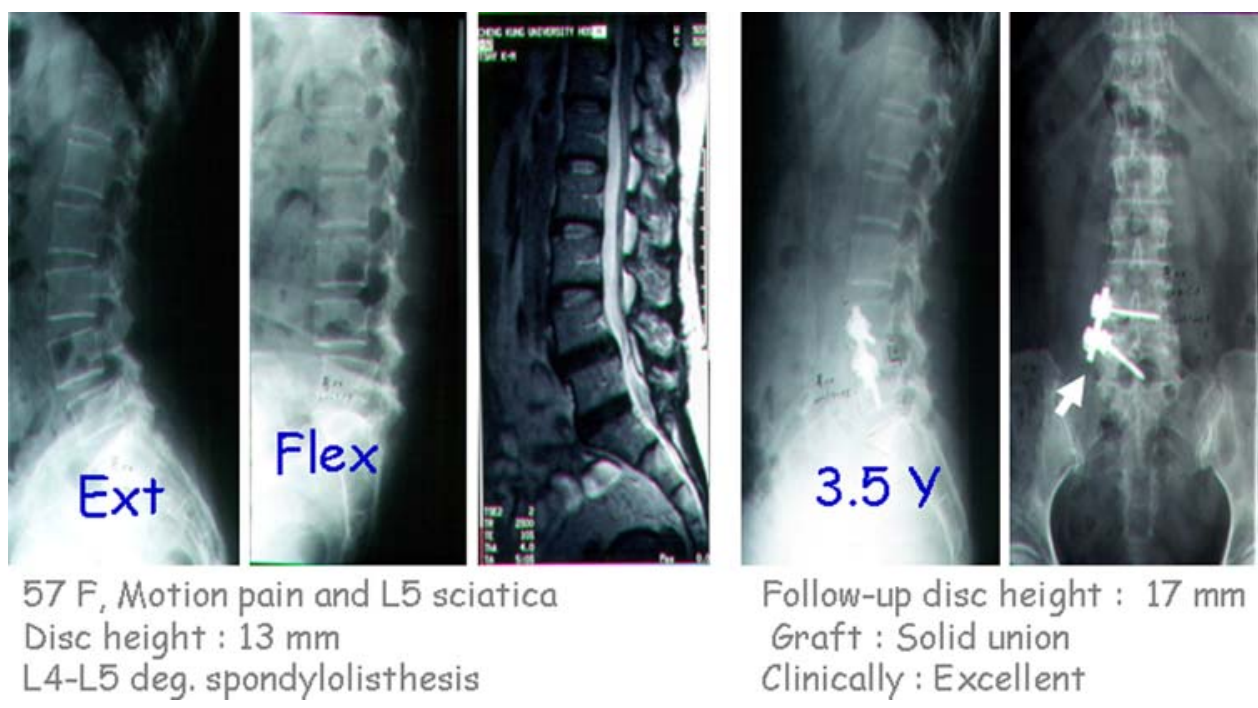

Follow-up disc height : $17 \mathrm{~mm}$ Graft : Solid union Clinically: Excellent 
Table 1 Results of bony fusion

\begin{tabular}{ll}
\hline Fusion grading by plain and F-E X-ray \\
\hline Fusion grading & Radiographic criteria \\
\hline 1. Solid: 48 cases $(78.7 \%)$ & $\begin{array}{l}\text { Bridging trabeculation } \\
\text { Lack of radiolucent line near } \\
\text { graft } \\
\text { No motion on F-E view }\end{array}$ \\
& $\begin{array}{l}\text { Incomplete radiolucent line } \\
\text { Minimal motion }(<50)\end{array}$ \\
2. Probable solid: 10 cases & Solid on one side \\
$(16.4 \%)$ & $\begin{array}{l}\text { Resorption } \\
\text { Great decrease in size }\end{array}$ \\
3. Failed: 3 cases $(4.9 \%)$ & Wide motion on F-E view $(>50)$ \\
& Full radiolucent line \\
\hline
\end{tabular}

without extra posterior instrumentation. Eight follow-up pyogenic spinal infections were clinically uneventful; five of these were fixed with one rod and two screws. One case had a noted slight upper screw migration, but without complaint (Fig. 3).

Mean disc height gain was $4.76 \mathrm{~mm}$ ( -2 to 30$)$ with a height loss at follow-up of $2.08 \mathrm{~mm}(0-10)$. The average angulation gain was $7.46^{\circ}$ ( -2 to 45$)$, while further angle loss was $3.69^{\circ}(0-26)$ (Table 2). There were 20 neurologically compromised vertebral fractures; most cases could maintain kyphotic correction with only one rod and two screws. The key to this is thought to be adequate interbody support by strut graft, mesh or hybrid (Fig. 4; Table 3).

There were no major complications, such as major vessel injury, ureter injury, urinary retention or retrograde ejaculation. Nine cases $(13 \%)$ had warm legs on the operative side, which lasted 3-7 days. Seven cases reported complications such as sagging abdomen (1), avulsion fracture of the anterior superior iliac spine (1) and graft resorption (3), dislodging (1) and sinking (1). One patient had a dislodged graft and implant pull-out that was revised through a conventional anterior approach.

\section{Discussion}

Minimally invasive surgeries including endoscopic surgery and mini-open surgery are current trend of spine surgery, and its main advantages are shorter recovery time and cosmetic benefits, etc. $[6,9,11]$. However, mini-open surgery is easier and less technique demanding than endoscopic surgery. The advantages of anterior over posterior spinal fusion are numerous, including the physiological loading, ease of dissection, reduced operation time and blood loss, noninterference with the potentially painful posterior elements of the lumbar spine, back muscle function, and avoidance of scarring within the spinal canal [23].

Anterior lumbar diseases means the etiologies of the diseases originated from anterior aspect of lumbar spine.

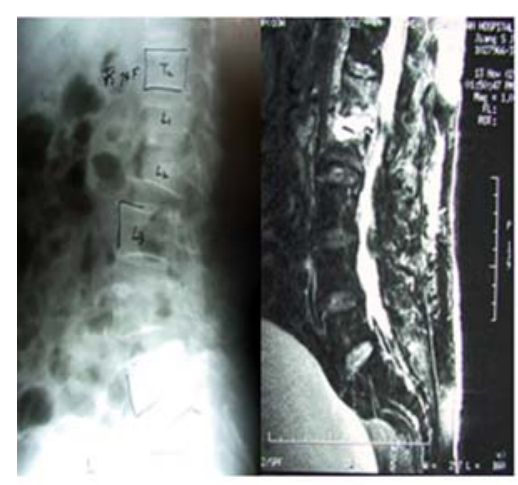

Preoperative X-ray and MRI

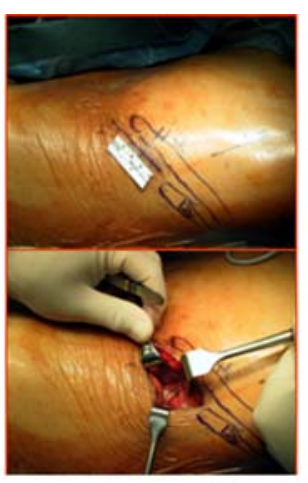

Incision $6 \mathrm{~cm}$ in length

Fig. 3 A 74 year-old female who suffered from L1-2 osteomyelitis (E. coli). She received debridement and anterior spinal fusion with autogenous tricortical bone grafts through mini-open surgery. Two

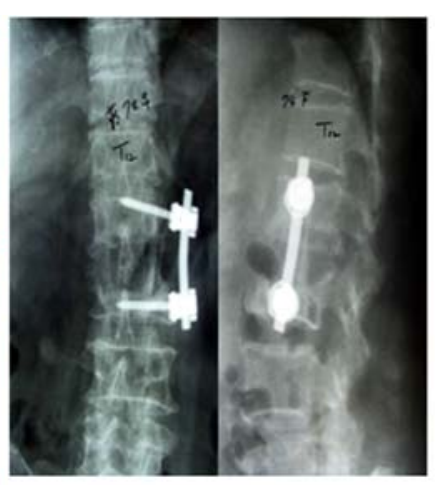

Immediately postop X-ray

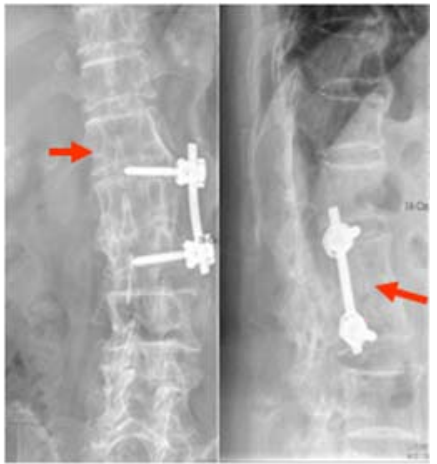

Two years' $\mathrm{X}$-ray

years later, there were no complaints or symptoms. Solid interbody fusion was noted, although the L1 screw migrated slightly (arrow)

Table 2 Radiographic lateral lumbosacral spinal changes, such as disc height gain, further height loss, disc angle gain, and further disc angle loss, after the MOASS technique with or without anterior instrumentation

\begin{tabular}{lcccc}
\hline $\begin{array}{l}\text { Lateral } \\
\text { X-ray }\end{array}$ & $\begin{array}{l}\text { Height gain } \\
(\mathrm{mm})\end{array}$ & $\begin{array}{l}\text { Height loss } \\
(\mathrm{mm})\end{array}$ & $\begin{array}{l}\text { Angle gain } \\
(\text { degrees })\end{array}$ \\
\hline Implant & 5.32 & -0.72 & 6.77 & $\begin{array}{l}\text { Angle loss } \\
(\text { degrees })\end{array}$ \\
No implant & 10.33 & -3.67 & 13.67 & -1.01 \\
\hline
\end{tabular}


Fig. 4 A 51-year-old female who received the MOASS technique for an old bursting fracture. A mesh stuffed with block allografts was used as the anterior support. Radiography 1 year later showed no loss of correction

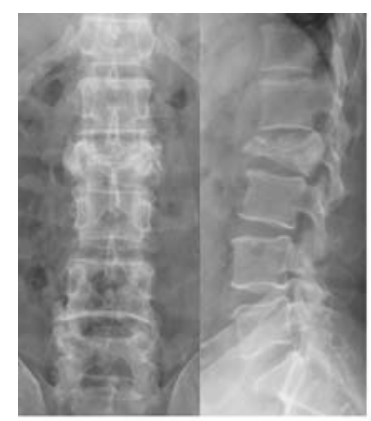

Preoperative X-ray

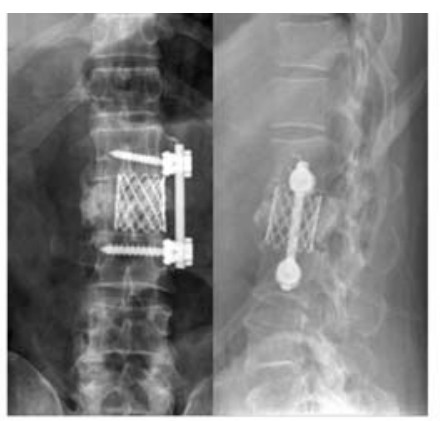

Immediate postop X-ray

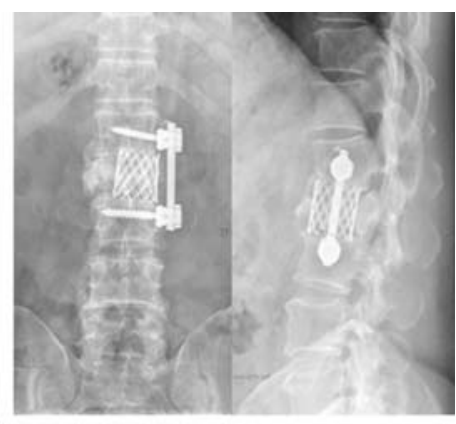

One year X-ray
Table 3 Subjective clinical results

\begin{tabular}{ll}
\hline Subjective clinical results & \\
\hline Categories & Criteria \\
\hline 1. Excellent: 40 cases $(65.6 \%)$ & $\begin{array}{l}\text { Satisfied with surgery } \\
\text { No residual symptoms } \\
\text { Returned to pre-injury activities } \\
\text { Satisfied with surgery } \\
\text { 2. Good: } 16 \text { cases }(26.2 \%)\end{array}$ \\
$\begin{array}{l}\text { Symptoms showed great } \\
\text { improvement }\end{array}$ \\
Not satisfied with surgery \\
Some residual symptoms \\
after the surgery
\end{tabular}

That's why we used the mini-open anterior spine surgery (MOASS) to treat patients with anterior lumbar diseases. MOASS technique can restore disc height at the anterior column and open up the neural canal and foramen, alleviating compression of the dural sac and nerve roots. In this study, the MOASS technique can increase disc height by $10.33 \mathrm{~mm}$, with a further loss of $3.67 \mathrm{~mm}$. Disc height elevation can increase spinal canal volume by $20 \%$ and the neural foramen area by $40 \%$ [5]. Lack of paravertebral muscle and facet joint dissection may also reduce the risks of subsequent junctional problems. Therefore, the MOASS technique is justified and an alternative for decompressing neurological compromise, alleviating the instability or mechanical pain of failed-back syndrome.

Since, in 1997, Mayer first reported a new microsurgical technique for minimally invasive anterior lumbar interbody fusion, it has spawned siblings in many fields [9, 20]. Although endoscopic approach is developing rapidly, miniopen approach is still considered better, especially for the retroperitoneal area [6, 19]. The endoscopic approach requires a long learning curve, usually by cadaver or animal model. Even an experienced surgeon would need a considerable amount of time. Loss of depth sensation, followed by complications, is not uncommon. This technique can also be quite frustrating [14, 19]. We prefer the mini-open approach like the MOASS surgical technique for anterior lumbar spinal diseases.

Solid bony fusion was obtained in $82 \%$ of patients with posterolateral lumbar fusion; $65 \%$ rated themselves significantly improved by the procedure while only $19 \%$ achieved a good or excellent Low Back Outcome Score. These results, however, were inferior to a similar series involving anterior lumbar fusion [13]. Compared to posterior spinal fusion, anterior spinal fusion is much better in terms of physiological loading, back muscle functions, nerve retraction and possible nerve adhesion $[14,25,26]$. A comparison study proved this point of view [23]. However, long-term surgical outcomes have been reported only for anterior fusion [22]. In the surgical technique of MOASS, we avoided ligation of the segmental artery; thus shortened operation time, decreased blood loss, and probably promoted bone fusion. We believe that the bone grafting technique was the key to stability, regardless of the graft used. Filling the decompressed space with strut graft materials was mandatory. Only one rod and screws fixation system was used for holding the grafts, and PMMA cement hybridized with interpore or cement grafts were sometimes used for augmentation of fixation in some osteoporotic patients. Our fusion rate $(95 \%)$ was better than those reported for combined anterior and posterior fusion [16], which possibly because of fusion technique and the preservation of segmental vessels. Using the MOASS surgical technique, we can effectively achieve anterior spinal fusion without additional posterior surgery in patients with anterior lumbar diseases.

Although no published studies have proven that this minimally invasive technique is superior to conventional ones, patients benefit from decreased postoperative pain, shorter hospital stays and earlier returns to work, as seen in our patients. In view of our results, the MOASS surgical technique can be applicable to various diagnoses, including vertebral fracture, failed back syndrome for supplemental or remedial fusion, segmental instability or spondylolisthesis, infection, herniated disc, undetermined lesion for biopsy and even resection of hemivertebra. 
Posterior lumbar microendoscopic discectomy and percutaneous lumbar discectomy are both feasible and effective treatments for disc herniation $[2,21]$. However, the MOASS technique provides an alternative for disc herniation especially in thoracolumbar junction, and can be considered for lateral artificial disc implantation in the near future.

Complications such as neurovascular injury, pre-sacral plexus injuries, ureter injury, urinary retention and retrograde ejaculation were absent from our series. However, one patient with mycotic aneurysm had maximum blood loss, but was successfully treated by in situ graft replacement. Nine patients had warm legs on the lesion side. The retraction screw and blade decreased the risks of vessel injuries and thrombosis. Normally, vascular injuries occur easily at the L4-L5 levels [1]. We obliquely inserted polyaxial screws and avoided ligating segmental vessels. None of our cases presented vascular injury, including those with L4-L5 lesions. However, there was still one case of abdominal muscle sagging, which might have been caused by traction neurapraxia of the abdominal nerves.

\section{Conclusion}

The mini-open anterior spine surgery (MOASS) technique is feasible, effective and safe for patients with various anterior lumbar diseases, including vertebral fracture, failed back surgery, segmental instability or spondylolisthesis, infection, herniated disc, undetermined lesion for biopsy, and hemivertebra, etc.

Open Access This article is distributed under the terms of the Creative Commons Attribution Noncommercial License which permits any noncommercial use, distribution, and reproduction in any medium, provided the original author(s) and source are credited.

\section{References}

1. Baker JK, Reardon PR, Reardon MJ et al (1993) Vascular injury in anterior lumbar surgery. Spine 18:2227-2230

2. Bonaldi G (2003) Automated percutaneous lumbar discectomy: technique, indications and clinical follow-up in over 1000 patients. Neuroradiology 45:735-743

3. Burkus JK, Foley K, Haid RW et al (2001) Surgical Interbody Research Group-radiographic assessment of interbody fusion devices: fusion criteria for anterior lumbar interbody surgery. Neurosurg Focus 10:E11

4. Capner N (1932) Spondylolisthesis. Br J Surg 19:374-386

5. Cheung KM, Zhang YG, Lu DS et al (2003) Reduction of disc space distraction after anterior lumbar interbody fusion with autologous iliac crest graft. Spine 28:1385-1389
6. Dewald CJ, Millikan KW, Hammerberg KW et al (1999) An open, minimally invasive approach to the lumbar spine. Am Surg 65:61-68

7. Duffield RC, Carson WL, Chen LY et al (1993) Longitudinal element size effect on load sharing, internal loads, and fatigue life of tri-level spinal implant constructs. Spine 18:1695-1703

8. Fairbank JC, Couper J, Davies JB et al (1980) The Oswestry Low Back Pain Disability Questionnaire. Physiotherapy 66:271-273

9. Foley KT, Holly LT, Schwender JD (2003) Minimally invasive lumbar fusion. Spine 28:S26-S35

10. Fraser RD (1982) A wide muscle-splitting approach to the lumbosacral spine. J Bone Joint Surg 64:44-46

11. German JW, Foley KT (2005) Minimal access surgical techniques in the management of the painful lumbar motion segment. Spine 30:S52-S59

12. Goel VK, Kim YE, Lim TH et al (1988) An analytical investigation of the mechanics of spinal instrumentation. Spine 13:1003-10011

13. Greenough CG, Peterson MD, Hadlow S et al (1998) Instrumented posterolateral lumbar fusion. Results and comparison with anterior interbody fusion. Spine 23:479-486

14. Heniford BT, Matthews BD, Lieberman IH (2000) Laparoscopic lumbar interbody spinal fusion. Surg Clin N Am 80:1487-1500

15. Ito H, Tsuchiya J, Asami G (1934) A new radical operation for Pott's disease. J Bone J Surg 16B:499-515

16. Kozak JA, O'Brien JP (1990) Simultaneous combined anterior and posterior fusion. An independent analysis of a treatment for the disabled low-back pain patient. Spine 15:322-328

17. Ley EB, Thurston WD (1954) Retroperitoneal approach to lumbar disc. Rocky Mt Med J 51:121-123

18. Lin SI, Lin RM (2005) Disability and walking capacity in patients with lumbar spinal stenosis: association with sensorimotor function, balance, and functional performance. J Orthop Sports Phys Ther 35:220-226

19. Liu JC, Ondra SL, Angelos P et al (2002) Is laparoscopic anterior lumbar interbody fusion a useful minimally invasive procedure? Neurosugery 51:155-158

20. Mayer HM (1997) A new microsurgical technique for minimally invasive anterior lumbar interbody fusion. Spine 22:691-699

21. Nakagawa H, Kamimura M, Uchiyama S et al (2003) Microendoscopic discectomy (MED) for lumbar disc prolapse. J Clin Neurosci 10:231-235

22. Penta M, Fraser RD (1997) Anterior lumbar interbody fusion-a minimum 10-year follow-up. Spine 22:2429-2434

23. Pradhan BB, Nassar JA, Delamarter RB et al (2002) Single-level lumbar spinal fusion: a comparison of anterior and posterior approaches. J Spinal Disord Tech15:355-361

24. Rajaraman V, Vingan R, Roth P et al (1999) Visceral and vascular complications resulting from anterior lumbar interbody fusion. J Neurosurg 91:60-64

25. Rauzzino MJ, Shaffrey CI, Nockels RP et al (1999) Anterior lumbar fusion with titanium threaded and mesh interbody cages. Neurosurg Focus 7:e7

26. Saraph V, Lerch C, Walochnik N et al (2004) Comparison of conventional versus minimally invasive extraperitoneal approach for anterior lumbar interbody fusion. Eur Spine J 13:425-431

27. Stauffer RN, Coventry MB (1972) Posteriolateral lumbar spine fusion. J Bone Joint Surg Am 54:1195-1204 